\title{
Recent patent applications in immunoassays
}

\begin{abstract}
Patent \# Subject
WO 9839652 Immunoassay for diagnosis of high alcohol intake in heavy drinkers and alcoholics; detects IgA antibody specific for acetaldehyde-protei adduct, using adduct of acetaldehyde and native protein fragment.

DE 19808930 Production of immunoassay for antigen or antibody comprising reacting captured analyte with particle-immobilized antibody or antigen.

EP 863153 New foam proteins crucial for head retention of beer, recognized by monoclonal antibodies used in immunoassays to assay foam protein content, head retention, and raw materials of beer, and to select stabilizer for beer.

US 5804404 New composition for chromogenic detection of peroxidase activity, e.g., in immunoassays and nucleic acid hybridization; uses components for increased stability of the composition during storage.

WO 9838513 Immunoassay providing greatly increased sensitivity, and thus early detection of disease markers, e.g., myosin, in cases of myocardial infarction; uses bispecific antibody reactive with analyte and polymeric probe carrying numerous copies of a label.
\end{abstract}

WO 9838511 Reactive compound for use as a tracer in immunoassays, comprising ouabain coupled to a compound labeled by radioiodine or fluorogen; useful for diagnosis of cardiovascular and endocrine diseases.

US 5801064 Single-chain Fv antibody specific for SS-A/Ro autoantigen; for immunoassay and affinity purification.

US 5801004 Prostate cancer diagnosis by immunoassay for steroid 5 alphareductase type 2 enzyme.

WO 9836277 Particle for use in a light scattering immunoassay, for measuring substance in biological fluids, and cell and tissue extracts for which immunological counter reactant can be produced.

WO 9835235 Immunoassay kit containing two antibodies recognizing coupled epitope(s) on collagen fragments; new antibodies for diagnosing arthritis, etc.; and prognosis and screening for anti-arthritic agents or inhibitors of matrix metalloprotease.

US 5792605 Immunoassay for antibodies to hepatitis A virus using three antibodies; Mitchell LA;

the detection limit is about $0.0015 \mathrm{mlU} / \mathrm{ml}$ of HAV-specific lgG antibody. Ochnio JJ

JP 10206427 Immunoassay method for thyroid, thyrotropic hormones; involves determining amount of antigen or antibody in test sample of depolarization after antigen-antibody reaction.

WO 9834109 Binding assay using differently labeled reactants for analyte and interferant; separation of bound and unbound phases and measuring both labels, particularly for use in immunoassays and hybridization assays.

US 5789185 Immunoassay for human interleukin-1 $\beta$ using two antibodies to avoid interference caused by phytohemagglutinin and endotoxin.

JP 10191974 A monoclonal antibody specifically reactive to human growth hormone; used in enzyme immunoassays for the determination of human growth hormone levels.

RU 2105981 Predicting the course of acute myocardial infarct; comprises investigation of receptor apparatus of neutrophils using immunofluorescent method.

JP 10170517 Immunoassay for measuring presence of antibodies in liquid samples; comprises adding another antibody to form immune complex and detecting; can be used in, e.g., blood serum.

Assignee
Pharmacia \& Upjohn
(Bridgewater, NJ)

Author

Hurme L,

Sillanaukee $P$

Worrall S

Asahi Kogaku Kogyo Mito A, KK (Tokyo); Nakayama M Nakayama M

Suntory Ltd. )

(Osaka, Japan

Dako Corp.

(Carpinteria, CA)

Khaw B; Narula J

Khaw B, Narula J

9/3/98 A1

Leppaeluoto PJ; Vakkuri LEO;

Vuolteenaho OJ

Foresman MD; Ghai J; Newman KZ

Hakky SI; Hudson PB; Lombardo ME

Dade Behring

(Newark, DE)

Univ. Sheffield (UK)

Croucher LJ, Hollander AP

8/13/98 A1

Leppaeluoto PJ, Vakkuri LEO,

Vuolteenaho OJ

Foresman MD, Ghai $\quad$ 9/1/98 A

J, Newman KZ

Hakky SI, Hudson PB, Lombardo ME

$9 / 1 / 98 \quad A$

Stout RW

8/20/98 A2

Toa lyo Denshi KK

(Japan)

Chiron Diagnostics

(Norwood, MA)

Mitchell LA

Ochnio JJ

$8 / 11 / 98 \quad A$

$8 / 7 / 98 \quad A$

Cistron Biotechnology Lisi PJ

$8 / 4 / 98 \quad A$

(Pine Brook, NJ)

Mitsui Petrochem Ind.

$7 / 28 / 98$

Co. Ltd. (Tokyo)

Univ. Sarat Med.

Cardiology Res.

Inst. (Russia)

Mitsubishi Chem.

Corp. (Tokyo) 